\title{
UM EXERCÍCIO DE DESCONSTRUÇÃO DO CONCEITO E DA PRÁTICA DE SEGMENTAÇÃO DE MERCADO INSPIRADO EM WOODY ALLEN
}

RESUMO

O conceito de segmentação de mercado constitui-se em uma forte ferramenta freqüentemente utilizada na tomada de decisão nas organizações. Neste artigo, busca-se analisar elementos nem sempre privilegiados quando se trata a segmentação de mercado como discurso hegemônico. A crítica aqui apresentada inspira-se no filme Desconstruindo Harry, de Woody Allen, o que permitirá compreender o exercício de desconstrução do conceito e da prática da segmentação de mercado com base no gênero e na etnia. Essa proposta ampara-se sobre o postulado de Derrida (1999) de que qualquer conceito, palavra ou significado léxico é passível de desconstrução e na hipótese de que o conceito de segmentação de mercado e sua prática encerram significados não revelados, guardando em si um conjunto de atores e vozes marginalizados.

\author{
Jorge Francisco Bertinetti Lengler \\ Doutorando em Administração na UFRGS e Professor do Departamento de Ciências Administrativas da UNISC. \\ E-mail: jlengler@zaz.com.br

\section{Marcelo Milano Falcão Vieira} \\ Doutor pela Universidade de Edimburgo (Escócia) e Professor do Programa de Pós-Graduação em Administração da UFRGS. \\ E-mail: mmfv@npd.ufpe.br

\section{Roberto Costa Fachin} \\ Doutor pela UFRGS, Professor e Coordenador Adjunto do Programa de Pós-Graduação em Administração da UFRGS. \\ E-mail: rcfachin@portoweb.com.br
}

\begin{abstract}
Market segmentation is a powerful marketing tool frequently used to support decision-making in organizations. In this paper we aim at analyzing some elements not always evident when one deals with market segmentation as a hegemonic discourse. We base our analysis in Woody Allen's "Deconstructing Harry", which allows the understanding of the deconstruction of market segmentation concept and practice based on gender and race. Such a purpose is supported by Derrida (1999) who tells us that every concept, word or lexical meaning is subject for deconstruction. Moreover, the hypothesis that both concept and practice of market segmentation hide unrevealed meanings, voices and social actors is central in our analysis.
\end{abstract}

PALAVRAS-CHAVE Desconstrução, discurso, segmentação de mercado, pós-modernismo. KEY WORDS Deconstruction, discourse, market segmentation, postmodernism. 


\section{WOODY ALLEN DESCONSTRUINDO HARRY}

Para falar de Desconstruindo Harry é preciso que se fale de Woody Allen. Acostumado à rispidez da crítica que por vezes não compreende seus filmes e a um segmento de público que idolatra sua obra, Allen não guarda qualquer semelhança com o film persona neurótico, conquistador frustrado, hipocondríaco e indeciso que povoa seus filmes. Ao contrário, trata-se de um autor disciplinado e capaz de tomar decisões que imprimem traços de obra de arte a seus filmes.

Recusando-se a comprometer sua arte e visão de mundo por caprichos de mercado, Allen ousa ao produzir seus projetos e não se impressiona em ser melhor recebido nas salas européias do que no grande mercado consumidor norte-americano.

Dos dramas urbanos explorados em Interiores, Manhattan e Hanna e suas Irmãs, passando pela comédia sem medidas de Bananas, Allen atinge seu auge no filme Descontruindo Harry, produzido em 1997 e que desfila um conjunto de celebridades do mundo cinematográfico da atualidade.

A falta de clareza, a fragmentação, a inexistência de uma narrativa homogênea e, sobretudo, a abordagem de temas relacionados às minorias, fazem a tônica da desconstrução da vida de Harry Block em pouco mais de uma hora e meia de projeção.

Não há preocupação com formas ou regras. A hierarquia tampouco é preservada. Allen dá lugar à "anarquia", à falta de sequência. Tudo transcorre em um grande simulacro em que a realidade é falseada pela composição de fatos, superposição de cenas e repetição de takes.

Em Desconstruindo Harry, a fronteira que separa obra e vida parece cada vez mais difusa entre a personalidade e a obra cinematográfica de Allen, o que, aliás, forma o estilo do roteirista que é acusado - ou estigmatizado de reproduzir nas telas fragmentos de sua vida pessoal.

$\mathrm{O}$ estilo do filme, que alterna momentos de ficção e realidade, mostra um escritor que usa seus amigos em histórias fictícias para recobrar-se de sua impotência literária. Desconstruindo Harry flutua entre os pólos da realidade e ficção de três mundos diferentes: o mundo que cerca o escritor; o mundo que flui na própria interpretação e, por fim, o que pertence aos fantasmas pessoais do escritor (Casas, 1998).

Allen filma e produz a montagem ao estilo de suas obras anteriores. Ele atua praticamente fora da cena e, manipulando a realidade, apresenta um sentimento dissonante do plano real, filmado. Esse tipo de artifício deixa clara a intenção do cineasta em instalar uma reali- dade paralela à vida dos personagens (Couto, 1999). A manipulação da realidade deixa transparecer um autor desencantado com a vida, que mostra incessantemente a fragilidade dos indivíduos. Mel, interpretado por Robin Williams, aparece desfocado em frente à câmera. Ao primeiro julgamento, a falta de foco poderia ser atribuída a um problema técnico, da câmera. Aos poucos, nota-se que não é um truque, mas sim um problema do próprio personagem, que aparece "desfocado no mundo real", fora do foco de sua vida. Essa seqüência poderia ser entendida como a essência do trabalho de Allen: os indivíduos são descentrados, ou fora de foco em uma realidade manipulada por constantes simulacros.

É justamente nesse aspecto que este artigo busca inspiração. Trabalha-se elementos que representam a falta de foco em indivíduos e grupos sociais que não se afinam com uma realidade desenhada e projetada por outros grupos sociais, ora dominantes na sociedade ocidental contemporânea.

\section{PÓS-MODERNISMO, DESCONSTRUÇÃO E SEGMENTAÇÃO DE MERCADO}

Desde que foi cunhado, o termo "segmentação de mercado" tem sido utilizado pelo meio acadêmico e empresarial como um instrumento capaz de fornecer subsídios para a tomada de decisão quanto ao composto mercadológico das organizações (Dickson e Ginter, 1987; Richers, 1991). No início, predominou a segmentação de mercados a partir da localização geográfica do consumidor. Posteriormente, foram introduzidas as questões relacionados às características psicográficas dos consumidores e aos benefícios esperados em relação ao produto (Haley, 1968, 1984).

Apesar da contribuição de tal construto para a gestão organizacional e para a consolidação de uma "teoria de marketing", neste artigo busca-se analisar elementos nem sempre privilegiados quando se observa a segmentação de mercado como discurso hegemônico. Não se trata, entretanto, de desconsiderar uma estrutura conceitual que foi erguida ao longo de mais de quatro décadas de esforço de pesquisa em uma prolífera comunidade acadêmica. Trata-se, sim, de olhar de outra forma o conceito, afirmando que a busca da categorização torna os indivíduos semelhantes ou, no extremo, iguais em comportamentos, hábitos e desejos. Neste artigo, rejeita-se essa idéia, ou seja, a idéia de um indivíduo autônomo, centrado, com uma identidade unitária segura, como o centro do universo social (Alvesson e Deetz, 1999). 
Mas, por que desconstruir um conceito que a literatura da área consolidou como discurso hegemônico para administradores e acadêmicos? Primeiro, porque o manto pós-moderno e sua significação permitem-nos acreditar que o conceito de segmentação de mercado e sua prática encerram significados não revelados, guardando em si um conjunto de atores e vozes marginalizados; segundo, porque Derrida (1967, 1999), um dos mais importantes autores pós-modernos, ensina-nos que toda palavra, predicado, conceito e significação léxica é passível de desconstrução (Stern, 1996b). Assim, se considerarmos como verdadeiros os argumentos pós-modernos de indivíduo e mundo fragmentados, heterogêneos, pluralistas, contraditórios e efêmeros, como aceitar fórmulas cartesianas e predeterminadas de classificação de comportamentos?

A preocupação deste esforço de desconstrução, entretanto, é mais profunda se considerarmos a hipótese de que o conceito de segmentação e suas práticas guardam em si um conjunto de significados que empurram para a margem grupos de indivíduos. Estes acabam por ser marginalizados por tal discurso hegemônico, em especial as minorias - que, sob a ótica de grupos consumidores, são vistas pela indústria como grupos "segmentáveis por suas características específicas". O que se sustenta, assim, é o posicionamento de que a segmentação de mercados por algumas bases específicas como etnia e sexo - são manipulações da própria intencionalidade mercadológica das organizações.

Além disso, embasamo-nos na crítica pós-moderna às metanarrativas, alvo central no dogma modernista, rejeitando aquilo que "parecia velho e ultrapassado" (Horton, 1995). As metanarrativas são esquemas histórico-filosóficos criados pela era moderna para explicar e legitimar os movimentos sociais. Em lugar das metanarrativas, sugerem os pós-modernistas, estão as "narrativas modestas", que não têm a pretensão de explicação do mundo, ou de validações externas, mas são válidas internamente nas comunidades de onde brotam.

Como Wood Jr. (1999) argumenta, na perspectiva pósmoderna o homem é um voyer navegando em um mar de símbolos, onde o que existe são discursos. A vivência é mediada por imagens de cinema e televisão carregadas de uma simbologia que guarda em suas entrelinhas muito mais do que os diálogos insinuam. "A realidade, como construção social, passa a ser julgada em face da contraparente cinematográfica" (Wood Jr., 1999, p. 269). Nessa sociedade de espetáculo, os espectadores são confundidos por realidades artificiais e simulações que falseiam o próprio mundo. A realidade é interpretada e, conforme os pós-modernistas céticos, tudo pode ser interpretado de diferentes maneiras, nunca havendo apenas uma interpretação.

\section{O MÉTODO}

Fazem-se exercícios de desconstrução para revelar significados. Assim como Woody Allen, em Desconstruindo Harry, exercita, desconstrói, desvenda facetas ocultas e não percebidas dos personagens, os pós-modernos também exercitam a desconstrução de conceitos - e, no caso deste artigo, o de segmentação de mercado -, permitindo descobrir facetas ocultas e não percebidas. Analogicamente, assim como desconstruiu-se Harry, busca-se aqui desconstruir a segmentação de mercado. A perspectiva pós-modernista usa técnicas, insights, métodos e abordagens de uma variedade de tradições, permitindo ao pesquisador ir, voltar, e ir novamente, sem muita preocupação com os limites acadêmicos. Dessa perspectiva do pós-modernismo, todos os estímulos são simultaneamente aceitos. O pós-modernismo não se limita ao desconstrutivismo como técnica, apesar desta ter sido considerada especialmente útil em seu projeto de compreensão do mundo. A análise do discurso e as genealogias foucaultianas também são utilizadas (Calas e Smircich, 1999).

A visão de mundo da pesquisa pós-moderna é essencialmente diferente do modelo modernista. A epistemologia da pós-modernidade focaliza tudo ao analisar um fenômeno, sem deixar qualquer elemento de fora do cenário - mesmo que este não seja central no discurso. A desconstrução, como forma de "leitura", analisa as particularidades de um texto julgando de forma crítica seus significados. Motivados pelo desafio da desconstrução de um conceito mercadológico hegemônico, buscamos identificar o que está nas entrelinhas, reconhecendo elementos obscurecidos pela força do discurso dominante.

O método da desconstrução, proposto por Derrida, foi adotado pelos pós-modernistas. Segundo Paul de Man, seguidor de Derrida e um dos maiores divulgadores da desconstrução como método de análise, o texto tem uma significação aberta que possibilita constantes modificações, em contraste com a concepção modernista de significados únicos e fechados (Stern, 1996b).

Desconstrução não quer dizer destruição. Quer dizer desmontar, para analisar e entender o real sentido do significante, as entrelinhas e os elementos subjacentes ao discurso que, quase sempre, têm a voz do contador 
da história (Boje e Dennehy, 1993; Foucault, 1998).

A proposta de desconstrução elaborada por Stern (1996a, 1996b) segue o leito de Derrida (1967), no qual é feita uma leitura aproximada do texto, usando-se a praxis da nova crítica - close reading - para analisar os significados e expor seus paradoxos e elementos não revelados, utilizando-se de atributos da linguagem, influências históricas e suposições culturais do texto. O procedimento dá-se pela exposição intertextual, pelo rompimento das hierarquias, pelo desmantelamento dos binários - entendendo "binários" como construções bipolares de termos e relações antagônicas, como apresentados por Boje e Dennehy (1993) -, revelando relações de poder e enfrentando a limitação dos significados presentes no texto.

Esse método será adotado para a desconstrução do conceito e da prática da segmentação de mercado por respaldar o pesquisador com uma teoria e uma história sobre a estrutura ou relação a ser desconstruída.

O método envolve a identificação de elementos textuais, a construção de significados e, por fim sua desconstrução, fase na qual o pesquisador desafia as perspectivas dominantes de significado.

A primeira fase tem a finalidade de permitir ao pesquisador a identificação dos atributos presentes no texto, tais como linguagem e personagens.

Posteriormente, a crítica desconstrutivista volta sua atenção para a revisitação do "o quê" do texto. A identificação de atributos e gêneros serve como impulsionador para a exploração desconstrutivista do que não é percebido, inconsciente e não-presente na superfície do significado.

\section{A CONSTRUÇÃO DO SIGNIFICADO: A LITERATURA DOMINANTE DE SEGMENTAÇÃO DE MERCADO COM BASE NO GÊNERO E NA ETNIA}

Considerada uma das ferramentas capitais do marketing, o conceito de segmentação de mercado começa a projetar-se no meio acadêmico e gerencial a partir da segunda metade do século passado, quando surgiram os trabalhos de Wendell Smith (1956) e de Engel, Fiorillo e Cayley (1972). Seu objetivo era claro: diante da impossibilidade de atingir todos os consumidores, seja devido à heterogeneidade de necessidades, valores, dispersão geográfica, gênero ou padrões culturais, as organizações direcionariam seus esforços para grupos específicos de consumo. Por meio dessa filosofia empresarial, fragmenta-se o mercado total em inúmeros micromercados, cada qual englobando consumidores que apresentam particularidades que os fazem semelhantes em termos de atitudes, comportamentos, valores, localização, etnia, sexo, uso e emprego dos produtos (Churchill e Peter, 1995).

Para que uma segmentação de mercado seja eficiente, deve haver uma escolha adequada das bases utilizadas para sua formulação. Interessa-nos, aqui, apresentar as bases institucionalizadas pela teoria de marketing para a segmentação de mercados consumidores com maior ênfase para as questões étnicas e de gênero.

O interesse de desconstrução recai sobre tal forma de segmentação justamente por ser esta uma das bases mais utilizadas no processo de divisão dos mercados consumidores. Embora empregada de várias formas, a etnia refere-se aos limites de um grupo étnico associados por seus valores, formas de vestir-se, religião, linguagem, entre outros.

\section{A DESCONSTRUCCÃO DO SIGNIFICADO: IDENTIFICAÇÃO E RECONCILIAÇÃO DOS BINÁRIOS}

Cabe-nos, aqui, desconstruir essa mensagem. Esta etapa envolve a desconstrução da noção simplista que se supõe estar subjacente ao conceito e prática da segmentação de mercado com base em variáveis étnicas e de gênero. Os binários serão elementos de análise que permitirão a comparação e revelação daquilo que é marginalizado no conceito, trazendo à tona elementos oprimidos pela prática do discurso dominante (Boje e Dennehy, 1993). A desconstrução é uma forma de tomar posição, em relação à estrutura política e institucional. Derrida (apud Stern, 1996b) ressalta que, como essa desconstrução nunca é unicamente relacionada ao conteúdo expresso e seu significado, ela não deveria ser separada da problemática político-ideológica que a envolve.

Os binários apresentados neste esforço de desconstrução expõem a natureza de um sistema hegemônico do conceito que revela os preconceitos da prática do construto hegemônico da segmentação de mercado.

Brancos e negros: dominador/dominado

O binário branco/negro revela uma dominação histórica presente nos textos e que deve ser tratada de maneira desconstrutiva, buscando o real significado da segmentação de mercado com base na etnia.

Considerando a emergência da população negra como 
um segmento de consumo, o setor produtivo passou a considerar esse grupo como uma possível oportunidade de mercado para seus negócios. É preciso, entretanto, que se considere tal processo do ponto de vista histórico. Da mesma forma como os negros norte-americanos, a história do negro no Brasil é marcada por escravidão, sofrimento e preconceito. Quando enfim libertos, os negros brasileiros pouco evoluíram em sua condição econômica (Furtado, 1989). Mais de cem anos após a assinatura da lei de libertação dos escravos, os resultados da situação exposta ainda refletem-se nas desigualdades entre negros, pardos e brancos. Hoje, ainda são claros os sinais de discriminação. Do total de negros da população brasileira, $81 \%$ estão no estrato social D e E, e 97\% têm renda inferior a dez salários mínimos (Grottera, 1997).

Percebe-se a discriminação em ações individuais, provérbios populares, enfim, no dia a dia da sociedade brasileira. Uma breve análise da história do país revela que a origem dessa desatenção e e desses preconceitos tem sido, até o presente momento, constante. Por vezes, defende-se a idéia de ser o Brasil uma democracia racial. No entanto, a realidade prova que o que existe é uma tolerância racial e a existência do preconceito (Alencar et al, 1985). O artigo publicado por Vicente Paulo da Silva, presidente do Instituto Sindical Interamericano pela Igualdade Racial, evidencia essa situação. Em sua manifestação, veiculada na Folha de S.Paulo (1998), Silva aponta, entre outros aspectos, a discriminação inconsciente e institucionalizada pela própria língua portuguesa por intermédio de expressões como "denegrir", "a coisa está preta", etc.

Entretanto, estimulada por cifras e prognósticos sobre o poder de compra da população negra no Brasil, o setor produtivo prepara-se. Os números referentes à população afro-brasileira por si só serviriam para justificar a importância de trabalhos que revelassem às empresas os padrões de consumo dessa parcela da população. De acordo com os resultados de pesquisa realizada pela agência Grottera (1997), os negros e pardos correspondem a 68,7 milhões de brasileiros, sendo a maior nação mestiça do mundo, superando, inclusive, a dos Estados Unidos (34 milhões) e até de nações africanas como a África do Sul (35 milhões) e o Zaire (45 milhões). A chamada classe média negra brasileira, que corresponde a 7 milhões de habitantes, percebe uma renda média mensal de $\mathrm{R} \$ 2.311,94$, totalizando uma renda anual de R $\$ 46$ bilhões, com cerca de R $\$ 6$ bilhões anuais excedentes para o consumo de produtos que não os considerados básicos. Em virtude de tal ce- nário, as indústrias de bens de consumo iniciaram na década de 1980 esforços para colocar no mercado produtos e serviços que atendessem às expectativas desse conjunto de consumidores.

As pesquisas de segmentação de mercado conduzidas por institutos autônomos e organizações interessadas em identificar um perfil étnico de consumo garantem que a falta de produtos direcionados para o segmento negro pode ser atribuída a um desconhecimento das diferenças culturais que representam tal grupo (Miller, 1993). Alguns desses estudos afirmam que os consumidores negros são mais leais a marcas quando adquirem alimentos, bebidas e produtos para a casa, privilegiando a qualidade do produto que consomem. O mesmo estudo destaca que ir às compras é uma das atividades preferidas desse segmento.

$\mathrm{Na}$ busca pela identificação das "necessidades" dos consumidores negros, institutos de pesquisa e empresas lançam-se ao mercado. Algumas pesquisas afirmam que "percebe-se despertar uma consciência de grupo entre os negros brasileiros e, como um grupo, tem suas necessidades, valores e aspirações de consumo específicas" (Grottera, 1997).

\section{A real significação do conceito e da prática de segmentação de mercado pela etnia \\ "...O escravo então foi deitar-se, \\ pois tinha de levantar-se \\ bem antes do sol nascer, \\ e se tardasse, coitado, \\ teria de ser surrado, \\ pois bastava escravo ser." \\ Castro Alves, "A canção do africano" (1960)}

Desigualdade: este poderia ser o vocábulo da língua portuguesa que melhor manifesta o distanciamento entre a cultura negra - dominada - e a branca - dominante. Sob tal binário, negro/branco, assenta-se uma estrutura de dominação subjacente às práticas de segmentação de mercado com base no componente étnico.

A desigualdade pode ser evidenciada de diversas formas na sociedade atual. O rendimento dos negros é, em média, $37 \%$ inferior ao dos brancos, enquanto os considerados pardos recebem rendimentos 32\% inferiores aos brancos (Grottera, 1997). Comparando-se a expectativa de vida dos brancos em relação à dos negros, verifica-se que os primeiros vivem, em média, 66,1 anos, enquanto os negros e pardos têm uma expectativa de vida de 59,4 anos.

Ávidas por novas oportunidades de mercado que pos- 
sam lhe render resultados positivos, as indústrias de bens e consumo lançam-se em busca do consumidor negro, colocando no mercado produtos e serviços específicos para esse segmento. A inquietação empreendedora do setor produtivo em conhecer esse "novo" consumidor revela os preconceitos.

Nota-se um esforço das organizações em atingir o consumidor negro com produtos e comunicações específicas, que atendam a suas necessidades. Entretanto, o que há de tão específico em consumidores negros que justifique a elaboração de produtos diferentes aos dos brancos? Tecnicamente, não há qualquer tipo de impedimento no uso de produtos "não segmentados para negros" por parte de pessoas da cultura afro-brasileira. Nesse sentido, sustenta-se que a segmentação de mercado por etnia ou raça guarda em si um apelo discriminatório, oriundo das relações sociais históricas entre negros e brancos, nas quais os primeiros desempenhavam papéis secundários ou dominados, enquanto o segundo grupo garantia o status quo de dominante, ou opressor.

Da forma como tem sido tratado pelo setor produtor de bens de consumo e serviços, o segmento de consumidores negros e pardos - ou não brancos - parece ter assumido o direito da condição soberana de consumidor, capaz de entrar no mercado de consumo e participar dos processos de socialização a partir do momento em que reuniu condições financeiras para tal. A forma como os meios de comunicação apresentam esse novo mercado coloca-o na condição de criador de demanda de novos produtos e serviços (Grottera, 1997).

O discurso dominante aborda a segmentação de mercado como demonstração de respeito às etnias consideradas minorias, como negros e pardos, por oferecerlhes valores por intermédio de produtos e serviços específicos.

A problemática dessa segmentação é a dominação de uma etnia em detrimento de outra, levando a um grau de etnocentrismo (Rocha, 1985, 1995). Não raros são os esforços de comunicação em diversos meios que reproduzem indivíduos de uma minoria étnica em condições típicas de indivíduos de grupos sociais dominantes - como a cultura waspie retratada por Tom Wolf (1987), ou seja, branca, anglo-saxã e de orientação religiosa protestante. A questão predominante é da exclusão de grupos do consumo de produtos e serviços que são destinados a outros grupos e indivíduos. Assim, o que se postula é que essa divisão do mercado não encontra uma condição suficiente para justificar a divisão de um grupo.

\section{Masculino/feminino: sexo dominante/sexo frágil}

A mesma condição de binário identificada para as questões étnicas - branco/negro -, pode ser reproduzida ao discutir-se a segmentação de mercado com base no gênero. Sem dúvida, este é um dos binários de maior destaque na desconstrução do conceito e da prática da segmentação de mercado, uma vez que a orientação para o grupo feminino de consumidoras tem sido mais efetiva nas últimas duas décadas. Munidos de pesquisas que apontam para um crescimento desse mercado consumidor no que se refere a bens de consumo duráveis e nãoduráveis, a indústria busca criar produtos que estimulem consumidoras a optarem por seus produtos. Institutos de pesquisas, como IBGE (1990) e Target, apontam para um crescimento das mulheres na população economicamente ativa brasileira. Em 1950, 85\% da PEA (população economicamente ativa) no Brasil eram de homens e apenas 15\% de mulheres. Em 1990, as mulheres já detinham 35\% das vagas do mercado de trabalho brasileiro. Com rendimentos crescentes, as mulheres ocupam cargos anteriormente destinados aos homens e têm nível educacional superior ao deles. Tom Peters (1998), especialista norte-americano em megatendências, afirma que a organização deve reavaliar todos seus processos, buscando conquistar esse mercado. A importância, segundo Peters, está nos números: nos EUA, 8 milhões de empresas pertencem a mulheres, cerca de $30 \%$ das mulheres casadas que trabalham fora ganham mais do que o marido. Elas representam 59\% dos cargos de professores assistentes em universidades e, por fim, gastam mais do que os homens com sapatos e equipamentos para esporte. Na mesma pesquisa, Peters concluiu que as mulheres tomam ou influenciam significativamente a maioria das decisões de compra do casal, no que diz respeito a moradia, assistência médica, automóveis ou pacotes de viagens.

Frente aos números, o mercado feminino constituise em um bom segmento a ser explorado pelas organizações.

A sociedade falocêntrica e a dominação subjacente no conceito e na prática da segmentação de mercado pelo gênero

"O sexo frágil representa o mercado mais forte da atualidade."

Peters (1998)

Apesar de comemorar os avanços obtidos pelas mulheres, a segregação sexual continua de diversas maneiras. A desigualdade remuneratória e de cargos deve ser 
considerada ainda como uma das mais contundentes formas de discriminação de gênero.

Pela forma como o tema é explorado, as organizações evidenciam em seus esforços de comunicação uma forma de discriminação da cultura ocidental: a dominação e supremacia do masculino sobre o feminino - a sociedade falocêntrica (Stern, 1996b). Em muitas das peças publicitárias veiculadas com o objetivo de conquistar o público consumidor feminino, seu personagem encontra-se em condições de submissão em relação ao homem. A mulher, via de regra, é retratada em campanhas publicitárias desempenhando atividades caracteristicamente submissas a personagens masculinos. Novamente, a história assume a lógica de quem a conta.

Em uma sociedade permeada de valores masculinos, as campanhas de comunicação empresariais seguem essa corrente. A submissão feminina torna-se evidente em atividades profissionais, nas quais a mulher é o agente excluído do processo decisório, relegado a atividades secundárias, cabendo aos homens a tomada da decisão. Esse tipo de segmentação do mercado traz em seu seio uma leitura discriminadora, do opressor sobre o oprimido, que deriva, sobretudo, da histórica supremacia masculina. Busca-se em Stern (1996b) um exemplo: o personagem Joe Camel, personificado nas campanhas publicitárias da companhia norte-americana de cigarros RJR, que mostram um mundo masculinizado, no qual a figura da mulher associa-se à subordinação e subserviência. Joe Camel, um camelo que assume a figura humana nas peças publicitárias de mídia eletrônica e impressa da empresa, tem o nariz em formato fálico, é maior que suas parceiras e desempenha papéis de maior prestígio que elas. Invariavelmente, as mulheres que contracenam com Joe Camel são garçonetes ou dançarinas que chamam a atenção por seus atributos físicos e não por suas características intelectuais.

$\mathrm{Na}$ divulgação de produtos de uso doméstico, tais como eletrodomésticos da linha branca, produtos de higiene e limpeza e até mesmo alimentos, a estrutura familiar patriarcal é mantida. O homem ocupa o papel principal nas histórias que são contadas, apesar da participação intensiva da mulher no mercado de trabalho, inclusive como maior renda do grupo familiar.

Os exemplos não cessam. A campanha publicitária dos produtos de higiene pessoal de um dos maiores fabricantes do gênero, veiculada na mídia eletrônica brasileira, retrata a situação que se descreve. O personagem feminino, nesse caso, pratica atos supostamente ilegais e é julgado por personagens masculinos que lhe conferem o direito à absolvição após interrogatório.
Novamente, a mulher é colocada em uma situação de inferioridade e subserviência à dominação falocêntrica do mundo.

Apesar do discurso feminista pregado pelas organizações, parece ainda não ter havido a ruptura definitiva do status quo definidor das relações de poder entre masculino/feminino no que se refere à prática do conceito de segmentação de mercado.

O método da desconstrução tem uma importante função na descoberta e revelação de elementos que ficam, por força de um sistema hegemônico, sufocados sob um elemento dominante. Essa dominação, de acordo com a Teoria Feminista Radical - uma das correntes feministas presentes no cenário da questão organizacional -, devese ao gênero, que se constitui em um sistema de dominação masculina, em um princípio que organiza as relação de opressão da sociedade e que está na origem de todos os sistemas de opressão. Os principais problemas citados aqui e relacionados à discriminação feminina são atribuídos aos privilégios garantidos ao gênero masculino em uma sociedade na qual o homem dominador é definidor das regras.

\section{CONCLUSÃO}

Por que desconstruir? Em que esse processo de desestabilização de um conceito relaciona-se à teoria de marketing? O argumento para tal desconstrução baseia-se no clamor da revelação crucial da relação entre poder, ideologia, historicismo e dominação. Essa revelação permite que se conte a história de outra forma, do ponto de vista do oprimido, descortinando o real significado dos textos. A desconstrução, nesse sentido, não deve ser separada da problemática políticoinstitucional que a envolve.

A partir da relação estabelecida pela confrontação da história contada por Woody Allen com a desconstrução empreendida neste estudo, pode-se sugerir que as estratégias de segmentação de mercado, empreendidas por uma comunidade acadêmica à procura de oportunidades de negócios em um mundo competitivo, reúnem em si um esforço quase niilista do self de grupos sociais específicos.

Não deve causar estranheza, portanto, a sustentação dos objetivos deste trabalho, que procura mostrar uma prática organizacional e acadêmica que, como constituinte de um discurso hegemônico, guarda em si poderosos fatores de opressão e submissão. Para esse entendimento, foi necessário utilizar a linguagem como siste- 
ma de significação, representando além daquilo que foi escrito ou dito. A contribuição de Allen, com Desconstruindo Harry, é significativa. Na inter-relação de diversos personagens, o filme do cineasta norte-americano busca debater temas como a submissão racial, de gênero e a supremacia religiosa por meio do confrontamento de opiniões conflitantes. A história é contada na forma de simulacros que falseiam a realidade e expõem a intenção de mostrar a face descentrada e esquizofrênica de seus personagens. A crítica ao conceito de segmentação de mercado assenta-se justamente sobre tais artifícios utilizados por Allen na desconstrução do personagem Harry Block.

Buscou-se revelar que por trás das práticas de segmentação está um comportamento de dominação. Negros e mulheres assumem a condição de destaque, e passam a ser notados, apenas quando seu lado de consumidor torna-se visível e contemporâneo. Grande parte do construto de marketing, sobretudo no que se refere à segmentação de mercado, é anterior à década de 1990, e é marcada pelo acorde monovocal da cultura waspie. Mais recentemente, novas correntes começaram a trazer luzes para a questão, buscando debelar a hegemonia de um mundo predominantemente branco, masculino e educado. Segundo Dholakia (apud Stern, 1996b), esse panorama de dominação do opressor sobre o oprimido mostra significativas mudanças: o exame de peças promocionais - histórias - sob a ótica dos que eram historicamente dominados tem revelado a voz oprimida das mulheres e dos negros.

O desmantelamento da supremacia masculina corrobora o enfraquecimento de outros binários que hierarquizam a sociedade ocidental. Agrega-se a isso o fato de que mais da metade dos habitantes de grandes países do continente americano, com maior ênfase nos Estados Unidos e no Brasil, irá se constituir de negros e pardos nos próximos dez anos. Essa mudança passa pela construção das identidades por meio da incorporação do self de indivíduos ou grupos específicos.

A questão feminista está em curso, sendo paulatinamente modificada. Entretanto, o tema das etnias dominadas ainda é subjacente ao discurso e à prática dominantes. Woody Allen soube trabalhar o propósito da revelação das vozes oprimidas. No primeiro momento, de identificação dos atributos da história, o personagem Harry contracena com uma prostituta negra. Na sequência da história, a identidade da mulher é resgatada com outra forma. Seu self foi alterado, retirando-se o fator hierárquico que a distancia dos personagens masculinos e brancos.
A exemplo da perspectiva feminista, a desconstrução de Allen revela sua crítica às metanarrativas. Em lugar destas, surgem as "narrativas modestas", que explicam a realidade peculiar de uma comunidade sem a pretensão de explicação do mundo. Tais narrativas funcionam como elemento de legitimação e auto-regulação local (Horton, 1995; Alvesson e Deetz, 1999). Enfrenta-se o que pode ser a forma de evitar essas discriminações presentes no conceito e na prática da segmentação de mercado. Tomando-se como base essas narrativas locais (petites narratives), tem-se uma forma própria para tratar as minorias oprimidas, sem que estas tenham de ser, como historicamente o são, vistas a partir das lentes de grupos dominantes hegemônicos. Pois, apesar da importância e significação que negros e mulheres têm na formação social e de mundo contemporâneo, suas identidades ainda são o reflexo da figura dominante.

O tema está aberto à discussão. Na área mercadológica, a prática da desconstrução e da revelação de conteúdos subjacentes aos discursos dominantes abre um grande campo de exploração acadêmica. Cabe-nos, então, a reflexão e o questionamento contínuos dos processos organizacionais que, legitimados por práticas de mercado, escondem a dominação dos que contam a história sobre aqueles que têm suas vozes omitidas.

\section{Artigo recebido em 22/03/2000. Aprovado em 23/07/2002.}

\section{Referências bibliográficas}

ALENCAR, F., CAPRI, L., RIBEIRO, M. História da sociedade brasileira. Rio de Janeiro : Livro Técnico, 1985.

ALVESSON, M., DEETZ, S. Teoria crítica e abordagens pós-modernas para estudos organizacionais. In: CLEGG, S., HARDY, C., NORD, W. (Orgs.). (Organizadores da edição brasileira: CALDAS, M., FACHIN, R., FISCHER, T.) Handbook de estudos organizacionais: modelos de análise e novas questões em estudos organizacionais.São Paulo : Atlas, 1999 v. 1.

BOJE, D., DENNEHY, R. Managing in the postmodern world: America's revolution against exploitation. Dubuque : Kendall/Hunt Publishing, 1993.

CALAS, M.B., SMRICICH, L.: Past postmodernism? Reflections and tentative directions. Academy of Management Review, 24, 4, 649-71, 1999

CASAS, Q. Enfoques y desenfoques. Dirigido, Ene., 1998.

CHURCHILL, G., PETER, J. Marketing: creating value for customers. Boston : Irwin, 1995.

COUTO, J. Filme discute a confusão entre a arte e a vida. Folha de S. Paulo, São Paulo, 11 jul. 1999. Caderno Ilustrada, p. 13. 
DERRIDA, J. Writing and difference. Chicago : University of Chicago Press, 1967. Disponível em: <http://www.hydra.umn.edu/derrida/arch.html>.

DERRIDA, J. Deconstruction: what is it? Disponível em: <http:// www.humanitas.ucsb.edu>. 1999.

DICKSON, P., GINTER, J. Market segmentation, product differentiation, and marketing strategy. Journal of Marketing, v. 51, Apr. 1987.

ENGEL, J., FIORILLO, H., CAYLEY, M. Market segmentation: concept and applications. New York : Holt, Rinehart and Winston, 1972.

FOLHA DE S. PAULO. União contra o racismo. São Paulo, 13 maio 1998.

FOUCAULT, M. A ordem do discurso. 4. ed. São Paulo : Loyola, 1998.

FURTADO, C. Formação econômica do Brasil. São Paulo : Companhia Editora Nacional, 1989.

GROTTERA. Qual é o pente que te penteia? O perfil do consumidor negro no Brasil. Relatório de Pesquisa, 1997.

HALEY, R. Benefit segmentation: a decision-oriented research tool. Journal of Marketing, v. 32, July 1968.

HALEY, R. Benefit segmentation: 20 years later. Journal of Consumer Marketing, n.2, 1984.

HORTON, M. The tower of Babel: modernity built the tower, now postmodernity must face the challenge of condemning the "unsafe structure". Modern reformation, Sept./Oct. 1995.

IBGE - Instituto Brasileiro de Geografia e Estatística. Censo demográfico brasileiro. Rio de Janeiro, 1990.

MILLER, C. Research says U.S. is more a bowl than a pot. Marketing News, May 1993.
MOWEN, J. Consumer behavior. $4^{\text {th }}$ ed. Englewood Cliffs : Prentice Hall, 1995.

PETERS, T. O poder das mulheres. HSM Management, Mar./Abr. 1998.

RICHERS, R. Segmentação, opções estratégicas para o mercado brasileiro. São Paulo : Nobel, 1991.

ROCHA, E. Magia e capitalismo. São Paulo : Brasiliense, 1985.

ROCHA, E. A sociedade do sonho: comunicação cultura e consumo. Rio de Janeiro : Mauad 1995.

SMITH, W. Product differentiation and market segmentation as alternative marketing strategies. Journal of Marketing, v. 21, July 1956.

STERN, B. Textual analysis in advertising research: construction and deconstruction of meanings. Journal of Adverstising, v. XXV, n. 3. Fall 1996(a).

STERN, B. Deconstructive strategy and consumer research: concepts and illustrative exemplar. Journal of Consumer Research, v. 23. Sept. 1996(b).

WOLF, T. A fogueira das vaidades. São Paulo : Círculo do Livro, 1987.

WOOD JR, T. Nota técnica: frutas maduras em um supermercado de idéias mofadas. In: CLEGG, S., HARDY, C., NORD, W. (Orgs.). (Organizadores da edição brasileira: CALDAS, M., FACHIN, R., FISCHER, T.) Handbook de estudos organizacionais: modelos de análise e novas questões em estudos organizacionais. São Paulo : Atlas, 1999. v.1. 